\title{
IMPLEMENTASI PEMBLOKIRAN TELEPON DAN SMS PADA PERANGKAT BERBASIS ANDROID
}

\begin{abstract}
Marlina
Abstract :

Nowadays, the usage of handphones is growing very quickly, so we can say that nearly everyone is now using the handphone. Handphone is used for voice telecommunication and for sending short message service (SMS), multimedia messaging service (MMS) and a lot of other smart aplications.

In the other hand, as the usage of the handphones grow, there are a lot of unwanted telephone call and SMS. Therefore, we need an aplication to block the unwanted telephone call and SMS.

This journal describe the implementation of a telephone and sms blocking application on the android based device.
\end{abstract}

Kata kunci: sms blocker, telephone blocker, android

\section{PENDAHULUAN}

Seiring dengan perkembangan zaman, maka terjadi peningkatan pemakaian telepon genggam, bahkan dapat dikatakan bahwa hampir setiap orang sudah memilikinya. Selain digunakan untuk urusan pribadi telepon genggam juga digunakan untuk urusan bisnis. Telepon genggam selain digunakan untuk menelpon juga banyak digunakan untuk mengirim SMS (Short Message Service), MMS (Multimedia Messaging Service) dan dipakai untuk aplikasi cerdas lainnya.

Disamping banyak kegunaannya, ada juga beberapa sisi negatif yang dirasakan yaitu:

1. Banyaknya telepon yang tidak dikenal yang menawarkan jasa. Misalnya kartu kredit, asuransi.

2. Dalam bisnis pemakai dapat bekerja sama dengan suatu operator untuk melakukan broadcast keberbagai nomor yang terdaftar pada suatu operator untuk mempromosikan suatu barang, atau jasa sehingga seringnya pengguna menerima SMS yang tidak dikenal yang berisi promosi.
3. Selain itu sering terjadi penipuan-penipuan lewat SMS dan telepon.

Modusnya bermacam-macam ada yang menjanjikan hadiah dengan mentransfer sejumlah uang sebagai pajak atau menginformasikan terjadi kecelakaan kepada anggota keluarga dimana harus segera mentransfer sejumlah uang agar dapat segera di operasi, bahkan ada juga yang meminta sejumlah uang dengan mengatas namakan oknum tertentu.

Akibat sisi negatif dari pemakaian telepon sering mengakibatkan keresahan, diakibatkan oleh SMS dan telepon yang tidak diinginkan, sehingga dibutuhkan suatu aplikasi yang dapat memblokir SMS dan telepon yang tidak diinginkan atau yang tidak dikenal.

Tujuan dari penulisan jurnal ini menganalisa prinsip kerja dari pemblokiran SMS dan pemblokiran telepon yang tidak diinginkan, dan akan diterapkan pada sistem operasi android yang dewasa ini sudah semakin banyak penggunanya. 


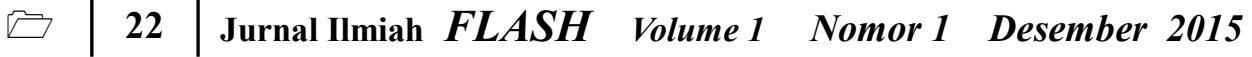

SMS (Short Message Service) mulai dikembangkan pada tahun 1991, dan sekarang SMS ini telah diterima secara global sebagai wireless service yang memungkinkan transmisi atau pengiriman pesan alphanumeric (teks) antar telepon selular. Meskipun SMS dibatasi hanya sampai 160 karakter saja, SMS ini adalah metode komunikasi non-voice yang tidak mahal.(Irwan, 2013)

\section{Multimedia Messaging Service (MMS)}

adalah sebuah standar layanan pesan telepon yang memungkinkan untuk mengirim pesan yang mengandung objek multimedia, seperti gambar, audio, video, dan rich text. Layanan ini berbeda dengan SMS (Short Messaging Service) yang hanya dapat mengirim pesan teks saja. MMS digunakan bersama-sama dalam sebuah jaringan selular dengan sistem perpesanan lainnya, seperti SMS, Mobile Instant Messaging, dan Mobile E-mail. (Triady, 2013)

\section{Android}

Android merupakan sistem operasi untuk telepon seluler yang berbasis Linux. Android menyediakan platform terbuka bagi para pengembang buat menciptakan aplikasi mereka sendiri untuk digunakan oleh bermacam peranti bergerak. Awalnya, Google Inc. membeli Android Inc., pendatang baru yang membuat peranti lunak untuk ponsel (Probawati, 2013).

\section{METODE PENELITIAN}

Untuk memblokir suatu SMS atau telepon yang ada dapat dengan cara:

1. Deteksi nomor telepon dari SMS atau telepon yang masuk. Apakah ada pada phone book atau tidak.

2. Jika nomor tersebut tidak ada pada daftar blokir maka pindahkan ke folder blokir.

3. Selanjutkan SMS tersebut akan dihapus.

4. Program selesai.
Ada 2 Cara pemblokiran Telepon, SMS dan MMS

1. Memblokir semua nomor telepon, SMS dan MMS yang tidak terdapat di database kontak.

2. Memblokir semua nomor telepon, SMS dan MMS yang sudah dimasukkan ke daftar yang hendak diblokir. Pemblokiran bisa juga bukan berdasarkan nomor kontak tetapi berdasarkan kata yang terkandung didalamnya.

Adapun flowchart adalah sbb:

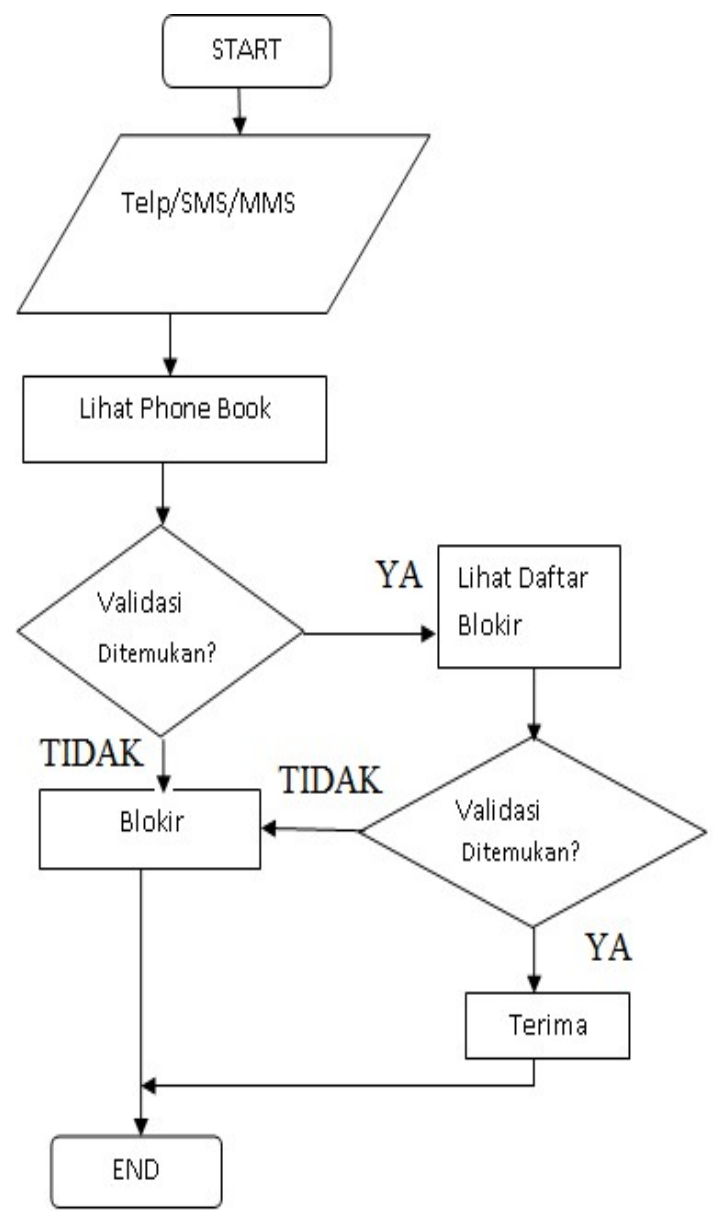

\section{HASIL DAN PEMBAHASAN}

Tampilan dari aplikasi yang digunakan untuk mengimplementasikan pemblokiran telepon dan SMS sebagai berikut: 
1. Memilih apakah yang akan diblokir telepon, SMS atau MMS.

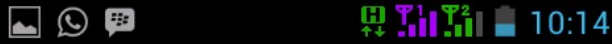

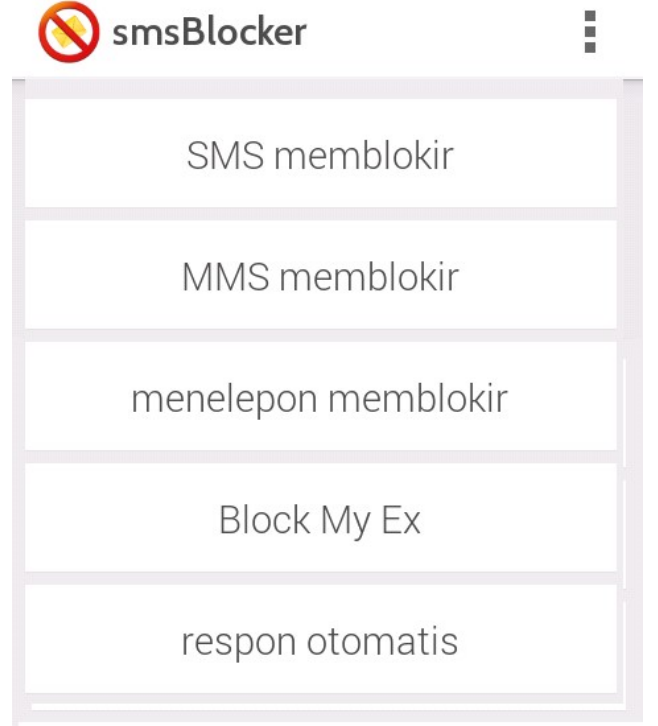

2. Memilih dan apakah yang akan diblokir konten kata atau no telepon, jika no telepon maka dapat diambil dari buku telepon atau diketik secara manual.

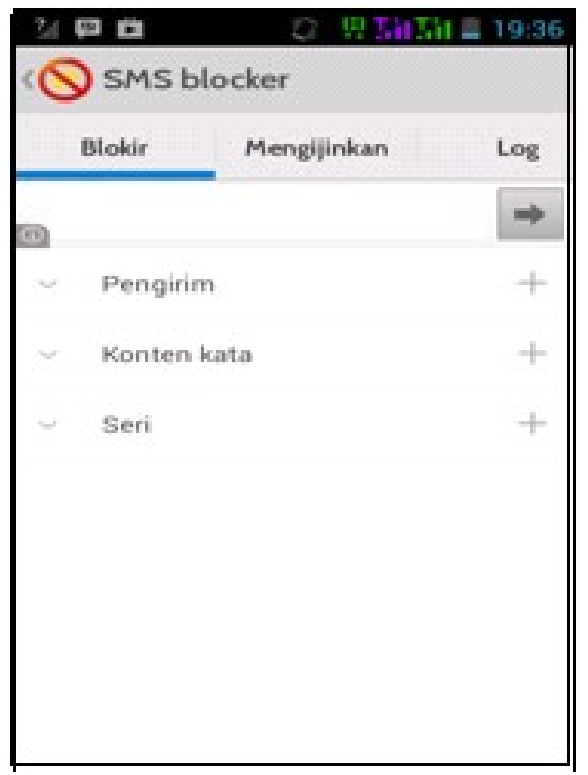

3. Memasukkan nomor-nomor telepon yang akan diblokir.

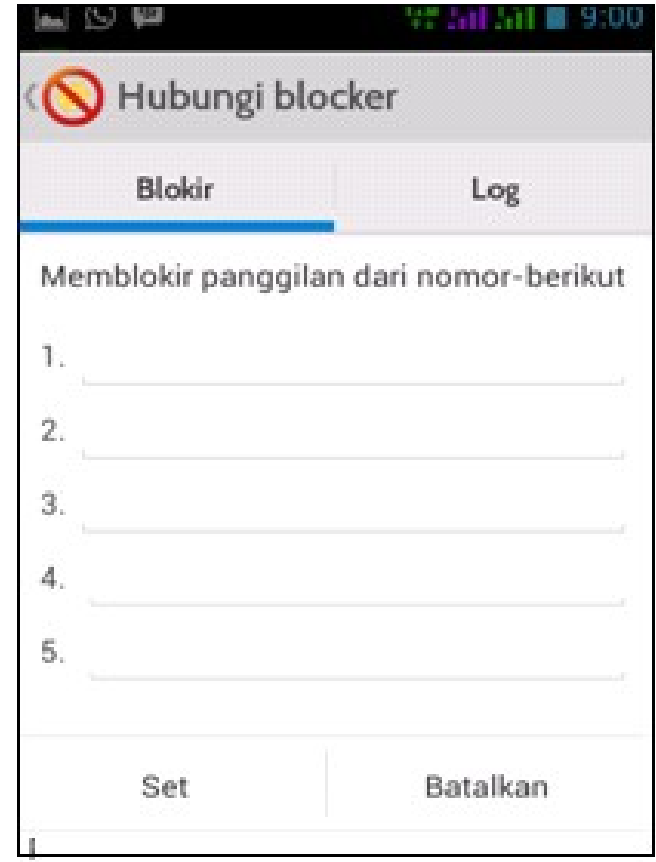

4. Setiap nomor telepon yang diblokir, jika mengirim SMS akan dipindahkan ke folder log, dimana dapat dilihat dan diatur apakah akan dihapus, atau tidak jadi diblokir.

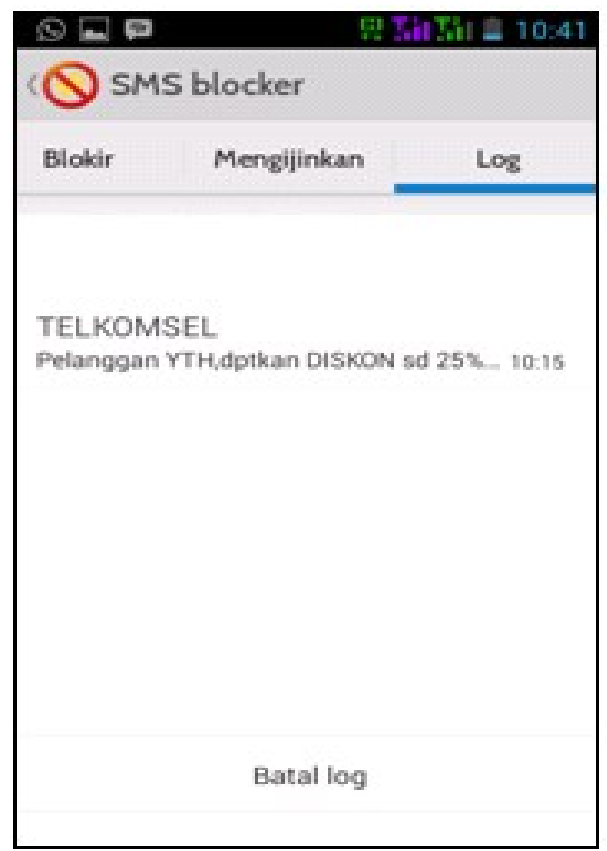




\section{\begin{tabular}{l|l|llll}
$\square$ & 24 & Jurnal Ilmiah $F L A S H$ & Volume 1 & Nomor 1 & Desember 2015
\end{tabular}}

Pengujian dilakukan pada sistem menggunakan metode Black Box yang akan memeriksa apakah sistem dapat berjalan dengan benar sesuai dengan yang diharapkan. Adapun teknik ujicoba yang digunakan dalam pengujian black box pada aplikasi ini, yaitu menggunakan teknik sample testing. Pengujian ini dilakukan pada proses input data. Selain itu, akan dilakukan pengujian kompatibilitas aplikasi dengan melakukan pemasangan aplikasi di dua perangkat handphone yang berbeda yaitu Cyrus menggunakan android versi 4.2.2 dan Samsung menggunakan android versi 4.2.1 baik.

Pada keduanya sistem berjalan dengan

Adapun hasil analisis dari implementasi pemblokiran telepon dan SMS pada perangkat berbasis android adalah:

1. Pengguna dapat melakukan pemblokiran baik SMS, telepon, MMS atau kesemuanya dengan memasukkan nomor telepon yang akan di blokir.

2. Pengguna dapat melihat isi dari SMS yang diblokir atau dapat juga mengatur agar SMS yang diblokir akan dihapus secara otomatis setelah kurun waktu tertentu.

3. Pengguna juga dapat mengembalikan nomor yang telah diblokir dikembalikan ke keadaan tidak diblokir.

\section{KESIMPULAN}

1. Dengan banyaknya telepon dan SMS yang tidak diinginkan, maka aplikasi pemblokiran SMS dan telepon sangat dibutuhkan oleh mayoritas pengguna telepon genggam.

2. Aplikasi yang diimplementasikan dalam jurnal ini dapat memblokir SMS maupun panggilan telepon, sesuai dengan daftar blokir yang diinginkan.

3. Walaupun SMS diblokir, namun SMS tersebut tidak dihapus, melainkan hanya dipindahkan ke dalam sebuah folder lain, sehingga pengguna dapat memastikan bahwa tidak ada SMS penting yang ikut terblokir.

\section{DAFTAR PUSTAKA}

1. Irwan, 2013. Jurnal Universitas TanjungPura, Vol. 1. ISSN 1693-2807.

2. Probawati, Arie, 2013, Tip Trik Android dan Blackberry, Andi.

3. Triadi, Dendy, 2013. BedahTuntas Fitur Android, Jogja Great. 